\title{
Inhaltsverzeichnis
}

MARTIN ROEBER

Vorwort

UTA FÖLSTER

Grußwort

1

\section{REGULA VENSKE}

Sprache als Verbrechen - Die Unterdrückung von Literatur und der Kampf des PEN für die Freiheit des Wortes

Mustafa Temmuz OĞLAKCIOĞLU

Im Netz ist alles erlaubt.

GIGI DEPPE

Recht, Bild, Sprache

HERMANN WEBER

Poesie des Frauenmords? - Georges Rodenbach, Dichterjurist unter den Dichterjuristen des belgischen Symbolismus

TONIO WALTER

Das Verbrechen in der Sprache des Gesetzes.

BURGHARD KREFT

Bach als Justiz-Subjekt.

MARKUS HIRTE

Mordballaden - vom Schinderhannes zu Rammstein und Nick Cave.... 109

ANHANG

AUTORENVERZEICHNIS

PROGRAMMANKÜNDIGUNG ZUM KONZERT 140 
